\title{
National food safety systems in the European Union: A comparative survey
}

\author{
Andreas Hadjigeorgiou ${ }^{a, b *}$, Elpidoforos S. Soteriades ${ }^{c, d}$, Anastasios \\ Philalithis $^{\mathrm{a}}$, Anna Psaroulaki ${ }^{\mathrm{e}}$, Yiannis Tselentis ${ }^{\mathrm{e}}$, and Achilleas Gikas ${ }^{\mathrm{f}}$ \\ ${ }^{\mathrm{a}}$ University of Crete, Faculty of Medicine, Department of Public Health \& Health Care Management, \\ Heraklion, Crete, Greece \\ b Ministry of Health, Public Health Services, Nicosia, Cyprus \\ ${ }^{\mathrm{c}}$ Harvard School of Public Health, Department of Environmental Health, Environmental and Occupational \\ Medicine and Epidemiology (EOME), Boston, MA, USA \\ ${ }^{\mathrm{d}}$ Cyprus Institute of Biomedical Sciences (CIBS), Department of Occupational and Environmental Medicine, \\ Nicosia, Cyprus \\ e University of Crete, Regional Laboratory of Public Health / Laboratory of Clinical Bacteriology, Parasitology, \\ Zoonoses, and Geographical Medicine (WHO Collaborating Center), Medical School, Crete, Greece \\ ${ }^{\mathrm{f}}$ University of Crete, Laboratory of Infectious Diseases, Crete, Greece \\ ${ }^{*}$ Corresponding author \\ ahadjigeorgiou@mphs.moh.gov.cy
}

Received: 9 July 2012; Published online: 18 April 2013

\begin{abstract}
This paper is a comparative survey of the National Food Safety Systems (NFSS) of the European Union (EU) Member-States (MS) and the Central EU level. The main organizational structures of the NFSS, their legal frameworks, their responsibilities, their experiences, and challenges relating to food safety are discussed. Growing concerns about food safety have led the EU itself, its MS and non-EU countries, which are EU trade-partners, to review and modify their food safety systems. Our study suggests that the EU and 22 out of 27 Member States (MS) have reorganized their NFSS by establishing a single food safety authority or a similar organization on the national or central level. In addition, the study analyzes different approaches towards the establishment of such agencies. Areas where marked differences in approaches were seen included the division of responsibilities for risk assessment (RA), risk management $(\mathrm{RM})$, and risk communication $(\mathrm{RC})$. We found that in 12 Member States, all three areas of activity (RA, RM, and RC) are kept together, whereas in 10 Member States, risk management is functionally or institutionally separate from risk assessment and risk communication. No single ideal model for others to follow for the organization of a food safety authority was observed; however, revised NFSS, either in EU member states or at the EU central level, may be more effective from the previous arrangements, because they provide central supervision, give priority to food control programs, and maintain comprehensive risk analysis as part of their activities.
\end{abstract}

Keywords: Control Agencies; European Union; Food Legislation; Food Safety; Reorganization; Risk Assessment; Risk Communication; Risk Management

\section{Introduction}

A steady supply of safe and good-quality food is one of the most fundamental basic human needs.
Many consider that it is the government's responsibility to satisfy the need for safe food for all (Lang, Millstone, \& Rayner, 1997; Taylor, 2004). Statistics on food-borne illnesses around 
the world point to the fact that poor-quality food has major financial and in some cases fatal consequences (Robertson et al., 2004). The lack of an effective National Food Safety Authority (NFSA) may have negative repercussions on public health, food safety, the national economy, the quality of life, the standard of food safety services, and overall economic development (Neeliah \& Goburdhun, 2007).

Governments have the responsibility of protecting consumer health as well as protecting consumers from fraudulent and deceptive practices in the food chain (de Jonge, van Trijp, Jan Renes, \& Frewer, 2007). The public health risks associated with food consumption are reduced or effectively controlled via a range of control mechanisms and activities (Boutrif \& Piniero, 2003). The above mechanisms include appropriate food legislation, established government standards, quality control measures such as HACCP, codes of practice adopted by the food industry, and regulatory controls applied by national and regional governments to all sectors of the food chain "from farm to table" (Kaferstein \& Abdussalam, 1999). It has been shown that the level of risk has an inverse relationship with the effectiveness of the above control measures. These controls could be better facilitated in the context of a well-organized and effectively operating National Food Safety System (NFSS) (Tselentis, 2008).

Although NFSA have been established to various extents among countries of the European Union, however these changes are considered beneficial for better organization of NFSS, as the majority of countries have used management techniques in developing and implementing their food control programs (William, 2000). The different elements of a NFSA may also suffer from some limitations; however, the revised NFSA of several EU countries may be more effective, despite certain mishaps, due to the priority given to food control programs based on comprehensive risk analysis (Maudoux et al., 2006). The literature supports the hypothesis that the separation of risk assessment and risk communication from risk management makes a positive contribution to improving the functionality and effectiveness of NFSS. The main reason being that such efforts provide a pivotal shield against economic and political in- fluences. However, the examination of the above hypothesis is an important topic for continued scientific discussion.

\section{Food Crises in Europe}

A number of old and new major food crises related in general with food safety (animal feed and animal production) show that any business dealing with food from primary production to final consumption should follow good manufacturing practices at all stages of the food chain (Lupien, 2002, 2007). Such crises illustrate that no country is immune from food safety problems, and that the food industry, even among developed countries in the European Union, may not always be vigilant, enough in following state-of-the-art practices (Terragni, 2006).

For example, a tragic incident occurred in Spain where adulterated olive oil was consumed and found responsible for a number of deaths and serious morbidity. However, subsequent investigations were not effective in identifying the origin of the toxic oils (Garcia \& Jukes, 2004).

A second highlighted event occurred in the United Kingdom (UK) where an epidemic of bovine spongiform encephalopathy (BSE), commonly called "mad cow disease", led to the slaughtering of thousands of cows. BSE also spread to some other European countries, Canada, and the United States of America. Atypical cases of Kreutzfeld-Jacob disease in the UK and other European countries were responsible for a number of human deaths and the food crisis was tentatively linked to the consumption of beef derived from BSE-affected cows (Wales, Harvey, \& Warde, 2006). Subsequent investigations showed that the probable cause of the disease in cattle were prion from rendered spinal and other products from sick or dead animals that were used for animal feeding (Mostl, 2003). Also in the UK, suspected feeding of uncooked food waste was identified as the probable cause of an epidemic of foot and mouth disease that led to the cremation of large numbers of cattle that seriously affected the economy of rural regions (Halkier \& L. 2006).

In Belgium and other EU countries animal feeds contaminated with high levels of dioxins, a carcinogenic pollutant, led to recalls of enormous 
amounts of animal products derived from poultry, eggs, and pork. The contaminated feed was also sold in parts of The Netherlands and France, and food products from all those countries were exported to many other countries, causing an international panic and leading to the loss of confidence in the effectiveness of the food industry and control authorities to protect the public (Berg, 2004; Maudoux et al., 2006).

\section{The Response of European and International Organizations to Food Scares}

Serious food crises during the 90 s forced the EU and EU Member States, as well as non-EU countries that are EU trade partners, to review their National Food Safety Systems (NFSS) in order to enhance their effectiveness and protect consumers against unsafe food (Post, 2006).

The occurrence of serious food crises in Europe, the legislative framework and organization of food safety in the EU central level and in the EU member states has changed and led to the reform of National Food Safety Systems (NFSS) in an effort to improve the operational effectiveness of the EU countries' food control mechanisms and ultimately provide effective protection to the health of the public (Neeliah \& Goburdhun, 2007). Such control systems are also vital in enabling countries to ensure the safety and quality of food products used in the international trade and to verify that imported food products meet national and international standards (Lupien, 2002; Garcia \& Jukes, 2004).

The Codex Alimentarius Commission continues to develop international standards, guidelines, and recommendations aiming to reduce food safety risks. Specifically, the Codex Commission developed risk analysis guidelines; the integrated food chain approach and HACCP (Millstone et al., 2000). The risk analysis paradigm, including risk assessment, risk management, and risk communication, has been incorporated as a general principle in EU law and forms the legal basis of the food safety systems in the EU Member States (Pina, Ferrer, Rodrigo, Klein, \& Martínez, 2006).

\section{The White Paper}

A White Paper, published in 2000, set out the principles on which the renewed policy would be based and the foundations of legislation would follow. An integrated approach was adopted across all sectors and at every level of the food chain ("White paper on food safety," 2000). The control approach from "farm to fork" was adopted as the official maxim of EU food safety policy. The role and responsibilities of all stakeholders in the food chain were defined, so that food, feed, and their ingredients would be traceable ("White paper on food safety," 2000; Gaynor, 2007).

The new food policy can be adaptable to help manage new developments and emerging risks, while all stakeholders would be involved. It is true that the precautionary principle and risk analysis are gradually becoming part of day-today activities in, at least, some national food safety agencies of EU countries. Nevertheless, according to Millstone and van Zwanenberg, 2000, 2002 risk analysis shall be at the center of food safety policy, and sound objective scientific advice shall be assured in the policy making process. However, further action is needed before these core issues are fully integrated in the national food policies of EU countries in a consistent fashion.

\section{General Food Law}

Food law and its accompanying regulations are the stepping-stones for a food safety system within each country. No legislation is of any worth, however, if it cannot be implemented and enforced (Boutrif \& Piniero, 2003). The general principles of the White Paper were translated into law within a regulation adopted by the European Council and Parliament in January 2002. The above law, now called the General Food Law, requires that "food shall not be placed on the market if it is unsafe", that is, if it is injurious to health or not fit for human consumption. This applies equally to food originating within the EU or imported into the EU (James, 2004). Moreover, all food business operators across the food chain must ensure that the food they place on the market meets the requirements of the food 
law with regard to production or distribution (Mostl, 2003; Gaynor, 2007). However, the answer on critical question how could food business achieves high standard in food safety is clearly define on the integration of HACCP and traceability across distances away from local production. Thus, the burden of responsibility is clearly placed on those involved in food production, who make a profit from it, and who are best placed to ensure food safety.

\section{European Food Safety Authority}

The General Food Law provided also the legal basis for the establishment of the European Food Safety Authority (EFSA) that provides independent scientific assessment and advice to EU decision makers. EFSA's responsibilities extend from carrying out scientific assessments to disseminating new information and networking with other scientific bodies, particularly those in EU Member States (Silano \& Silano, 2007). EFSA declared that it carries out its activities openly and without secrecy, publishing its opinions and all information on which opinions are based. However, the evidence available suggests that statements made by EFSA are not being consistently applied. Although it has a responsibility for risk assessment, EFSA does not have a regulatory function (Elmi, 2004). At the EU level, this division of responsibilities is crucial, as these political institutions are accountable to the European consumers.

\section{National Food Safety Agencies}

National Food Safety Systems (NFSS) constitute a group of elements organized and arranged in such a way that they can act as a whole to protect consumers' health (Berman, 2001). NFSS also are essential to protect consumers from fraudulent practices, thereby preserving their economic rights. In general, an effective NFSS assists economic growth in each country by maintaining consumer confidence in the food industry and national food controls and ensuring fair trade of food products nationally and internationally (Neeliah \& Goburdhun, 2007). NFSS are thus essential in every country because they are likely to contribute to increased food quality and the control of adulteration, contamination, and the risk of food-borne illness.

NFSS involve the participation of different entities for the achievement of consumer protection and fair trade. It is difficult to point out a single successful model that could be duplicated by other countries (WHO, 1992, 2001). However, the establishment of a single food safety agency, or a similar organization on the national level from the majority of the EU Member States, in order to facilitate interaction, cooperation, and supervision between the different bodies involved in food control could be considered as a useful contemporary model (Lenz, 2006; Neeliah \& Goburdhun, 2007). Furthermore, guidelines on the above issued by FAO/WHO (FAO/WHO, 2003; WHO, 2001) can be adjusted to fit particular country needs.

The objective of our study was to perform a comparative survey of the current National Food Safety Systems in the European Union Member States and compare the different operational approaches used around Europe.

\section{Methods}

\subsection{Methods}

For the purposes of this study, we defined consolidation as the transfer of responsibility and resources for performing a food safety function from two or more agencies to a single agency or a similar organization on the national or central level. Furthermore, we defined independent food safety agency as a stand-alone agency that reports directly to the parliament or to another equivalent national body through the Ministry of Health or when it is accountable to a third Ministry (without interests in food marketing) or when it is accountable to two or more Ministries.

A scientific literature search was carried out in order to document the alternative approaches occurring in EU countries regarding their national food safety systems. Scientific information was extracted from WHO/FAO technical papers, food and veterinary office country profile reports, the German Federal Institute for Risk Assessment reports, handbooks from the 
Codex Alimentarius Commission, the U.S. General Accounting Office reports, journal articles, electronic resources, and official websites of European institutions and national food safety authorities of EU countries. We focused our survey on the 27 countries, which are members of the European Union. We have implemented our survey by using a structured questionnaire, which facilitated the collection of information from several official public sources. The questionnaires for all EU countries were completed in 2010. Information from the food safety systems at the EU central level and the EU Member States was used to build a structured questionnaire. As a transitional stage, the bank of information was used to develop a comparative table in order to examine the main characteristics of the food safety systems, their competent authorities and the division of food safety responsibilities. The information was then categorized and compared in order to document similarities and differences on common problem areas and to list measures taken by different countries in revising their systems.

\section{European Union Countries}

The sample for our survey included the European Union at the central level and the 27 EU Member States. A group of countries (Denmark, Germany, Ireland, France, The Netherlands and the United Kingdom) was used as a comparison sample in order to evaluate the food safety systems of other European countries based on the following predetermined criteria: The above countries have introduced advanced institutional reforms and have consolidated their food safety systems. In addition, they were the first countries to proceed to the above changes, and their National Food Safety Systems are considered among the most successful in the European Union.

\section{Results and Discussion}

\section{$3.1 \quad$ Results}

The European Union at the central level and 22 out of 27 Member States $(81.5 \%$ ) have already established a single food safety authority or a similar organization (Table 1). Also in
Table 1, we present the year of establishment of each National Food Safety Authority for the EU countries. The countries that did not yet proceed to major institutional changes are Italy, Poland, Slovakia, Slovenia and Cyprus representing $18.5 \%$ of all European countries in terms of population. However, Italy is beginning to make concerted efforts towards such revision. Furthermore, the EU at the central level and 21 out of 22 EU countries $(95.4 \%)$, which implemented institutional reforms of their food safety systems, did so after 1996.

The results also revealed that 15 Member States $(55.6 \%)$ maintained all 3 sector activities under the same umbrella organization, namely risk assessment, risk management, and risk communication, while the other 12 Member States Austria, Bulgaria, Denmark, Estonia, Finland, France, Germany, Hungary, Lithuania, The Netherlands, Poland and Slovakia (44.4\%), have separate functional or institutional activities for risk assessment and risk communication as compared to risk management.

Our results also showed that the majority of Member States, 16 out of $27 \mathrm{EU}$ countries $(59.2 \%)$, publish the results of risk assessment on the internet. It is important to note that from these 16 countries, 14 of them $(87.5 \%)$ are among those, which implemented institutional changes in their food safety systems and particularly established a food safety authority on a national level.

In Table 2, we present information on the Ministries that supervise the national food safety agencies in each EU country. Eight countries $(29.6 \%)$ have placed their new agencies under the Ministry of Agriculture (Denmark, Finland, Hungary, Czech Republic, Estonia, Latvia, Romania, and Greece). Countries such as Sweden, United Kingdom, Germany, Belgium, Lithuania, and Malta $(22.2 \%)$, provided their agencies with an independent or semi- autonomous status. For instance, in the case of UK, the Food Safety Standards Agency (FSA), although it is a Government agency under the Health Department, it works at 'arm's length' from Government because it does not report to a specific Minister and is free to publish any advice it issues. FSA is accountable in England to the Parliament through the Health Minister, and to the devolved admin- 
Table 1: Year of establishment of national food safety authorities or other similar organizations on the national level for each European country.

\begin{tabular}{lrc}
\hline Year (EU country) & Frequency & Percentage \\
\hline Before 1996 (Sweden) & 1 & $4.5 \%$ \\
1997 (Denmark, Czech Republic) & 2 & $9.1 \%$ \\
1999 (France, Ireland) & 2 & $9.1 \%$ \\
2000 (United Kingdom, Belgium, Estonia, Lithuania) & 4 & $18.1 \%$ \\
2001(Spain) & 1 & $4.5 \%$ \\
2002 (Germany, Austria, The Netherlands, Latvia, Malta) & 5 & $22.7 \%$ \\
2003 (Hungary, Greece) & 2 & $9.1 \%$ \\
2005 (Portugal, Romania) & 2 & $9.1 \%$ \\
2006 (Finland) & 1 & $4.5 \%$ \\
2007 (Bulgaria, Luxembourg) & 2 & $9.1 \%$ \\
\hline Total & $\mathbf{2 2}$ & $\mathbf{1 0 0 \%}$ \\
\hline
\end{tabular}

Table 2: Accountability of national food safety authorities in the European Union.

\begin{tabular}{lcc}
\hline Accountability & Frequency & Percentage \\
\hline Independent / Parliament & 6 & 22.2 \\
Ministry of Health & 3 & 11.1 \\
Ministry of Agriculture & 8 & 29.6 \\
Other third Ministry & 1 & 3.7 \\
Two Ministries: Health and & 3 & 11.1 \\
Agriculture & & \\
Three Ministries: Health, Agriculture and Finance & 1 & 3.7 \\
\hline \multicolumn{1}{c}{$\quad$ Sub total } & $\mathbf{2 2}$ & $\mathbf{8 1 . 5}$ \\
\hline \multicolumn{1}{c}{ Rest of EU countries $\quad \mathbf{5}$} & $\mathbf{1 8 . 5}$ \\
\hline \multicolumn{1}{c}{ Total } & $\mathbf{2 7}$ & $\mathbf{1 0 0 . 0}$ \\
\hline * & &
\end{tabular}

istrations in Scotland, Wales, and Northern Ireland for its activities within their areas.

Three countries (11.1\%) - Spain, Ireland and Bulgaria - placed the new agencies within the corresponding Ministry of Health, and three more countries $(11.1 \%)$ - The Netherlands, Austria, and Luxembourg - placed their new agencies jointly under the Ministry of Health and the Ministry of Agriculture. Finally, one country (3.7\%) - France - placed the new food safety authority under the responsibility of three ministries, the Ministries of Health, Agriculture, and Finance. In Table 3, we present information on the assignment of responsibilities within each national food safety agency.

\subsection{Discussion}

The increasing concern about food safety has led the European Union and the majority of the EU Member States, as well as some countries which are EU trade partners, to modify their national food safety systems, in an effort to improve their effectiveness (Springston \& Weaver Lariscy, 2005). The results of our study show that the $\mathrm{EU}$ at the central level and the majority of EU countries has already established a single food safety authority or a similar organization on the national level. The EU countries that have not yet arrived at these institutional changes include Italy, Poland, Slovakia, Slovenia, and Cyprus, 
Table 3: Analytical description of the division of responsibilities within each national food safety authority*

\begin{tabular}{|c|c|c|c|c|c|c|c|}
\hline 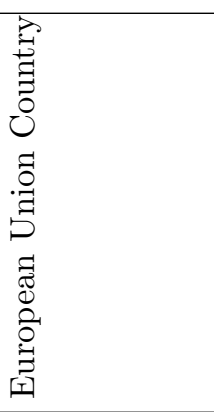 & 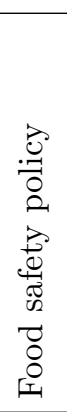 & 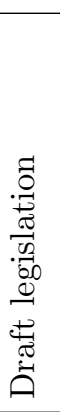 & 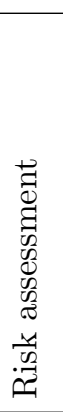 & 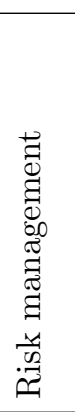 & 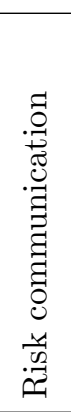 & 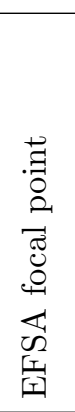 & 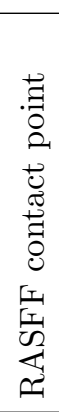 \\
\hline Austria & 0 & 0 & 1 & 0 & 1 & 1 & 1 \\
\hline Belgiu & 0 & 0 & 1 & 1 & 1 & 0 & 1 \\
\hline Bulgar & 0 & 0 & 1 & 0 & 1 & 1 & 0 \\
\hline Czech Rep. & 0 & 0 & 0 & 1 & 1 & 0 & 0 \\
\hline Denma & 0 & 0 & 0 & 1 & 1 & 1 & 0 \\
\hline Eston & 0 & 0 & 1 & 1 & 1 & 0 & 1 \\
\hline Finlan & 0 & 0 & 1 & 1 & 1 & 1 & 1 \\
\hline Fran & 0 & 0 & 1 & 0 & 1 & 1 & 1 \\
\hline Germany & 0 & 0 & 0 & 1 & 1 & 0 & 1 \\
\hline Greece & 0 & 0 & 1 & 1 & 1 & 1 & 1 \\
\hline Hung & 0 & 0 & 1 & 0 & 1 & 1 & 1 \\
\hline Irela1 & 0 & 0 & 1 & 1 & 1 & 1 & 1 \\
\hline Latvi & 0 & 0 & 1 & 1 & 1 & 1 & 1 \\
\hline Lithu & 0 & 0 & 1 & 1 & 1 & 0 & 1 \\
\hline Luxembourg & 0 & 0 & 1 & 1 & 1 & 1 & 1 \\
\hline Malta & 0 & 0 & 0 & 1 & 1 & 0 & 1 \\
\hline Netherlands & 0 & 0 & 1 & 1 & 1 & 1 & 1 \\
\hline & 0 & 0 & 1 & 1 & 1 & 1 & 0 \\
\hline oman & 0 & 0 & 1 & 1 & 1 & 1 & 0 \\
\hline & 0 & 0 & 1 & 1 & 1 & 1 & 1 \\
\hline & 0 & 0 & 1 & 1 & 1 & 1 & 1 \\
\hline U. K. & 1 & 1 & 1 & 1 & 1 & 1 & 1 \\
\hline
\end{tabular}

* Number "0" represents lack of the corresponding activity in each national food safety authority or similar organization while number "1" represents its presence. which represent $18.5 \%$ of the EU countries. Particularly, in case of Cyprus while food supply is generally safe, the food safety system remains unchanged with food safety be governed by a complex and fragmented system that is administered at least from three governmental agencies and autonomous municipalities (Hadjigeorgiou et al., 2012). Other countries such as Canada, Norway, Iceland, Argentina, Australia and New Zealand that are trade partners with the EU have also reorganized their national food safety systems (GAO, 1994, 1999; Neeliah \& Goburdhun, 2007; "BfR / EFSA Focal Point," 2009).

All EU countries, and EU at the central level, have initiated the above changes after 1996, except Sweden, which is the only country that had introduced a centralized national food safety system long before the other European countries (in1972). It is likely that the above reforms were ignited by repeated food crises however; additional reasons include the countries' goal to restore public confidence in the food industry and the food safety authorities, to improve program effectiveness, to cope with intensive requirements of modern food trade, to comply with European food regulation, and to effectively handle future food crises.

The most important differences seen between EU countries referred to the division of responsibilities assigned to the different national food safety systems regarding risk assessment, risk management, and risk communication (Lenz, 2006; "BfR / EFSA Focal Point," 2009). The European Food Safety Authority at the central level has maintained the duties of risk assessment and risk communication, while the risk management part, which blends with the political agenda, belongs to the European Commission and the Council of the European Union (Gaynor, 2007). Fewer differences were documented with respect to the publication of the risk findings on the internet, where most of the countries had similar policies, as the majority of EU Member States publish the results of their risk assessments on the internet. Some exceptions to the above rule applied when particular legal provisions prohibit such publication. It is important to note that, from these 16 countries, 14 countries (87.5\%) are among those that implemented institutional changes in their food safety systems and particularly established 
a food safety authority on the national level. Therefore, it is reasonable to conclude that the institutional reforms introduced in many EU countries have contributed to greater transparency and openness, placing the consumers' health among their main priorities. Direct twoway communication by means of exchange of views and opinions during risk analysis procedures is exercised between all stakeholders (assessors, managers, food businesses, the scientific community, and consumers), as well as other external bodies such as EFSA. Information sharing from National Food Safety Authorities in EU countries, including the explanation of risk assessment findings, is an essential component of an effective public health organization that works positively for the protection of consumer health and their interests (Fuentes, 2010).

Based on a number of characteristics, several countries in the EU are considered pioneers with respect to their food safety systems: Germany, France, The Netherlands, Denmark, United Kingdom, and Ireland. The above countries have consolidated their food safety systems and advanced their institutional reforms by establishing a single authority at the national level to lead all food safety functions (GAO, 1999). Some, countries as U.K. and Ireland, retain the above three functions under the same roof, whereas others tried to separate risk assessment from risk management by establishing two separate bodies. In addition, the above countries have modified their existing food safety legislation in order to give powers to the new authority, although their approaches and the extent to which they were consolidated differed. The particular countries belong to the high-income country category where consumers have high expectations for food safety and spend a relatively small percentage of their income on food (Regmi \& Bernstein, 2003; World Bank, 2004). On the contrary, in low-income countries, consumer spending on food often exceeds $50 \%$ of their total spending, in contrast to a range of $13-16.5 \%$ spending among the above six countries.

The major factors motivating countries to enhance their food safety systems were public concern about food safety and a general need to improve program effectiveness (Butler, 1997). For example, in the United Kingdom (UK), consoli- dation occurred mainly in response to the loss of consumer trust resulting from the food crisis of "mad cow disease" (Wales et al., 2006). UK in 2000, established a new agency called the Food Standards Agency (FSA). According to FSA officials, the Agency has the power of an agency in a ministry, but is not part of a ministry. It is instead held accountable to the corresponding UK parliaments of England, Scotland, Wales, and Northern Ireland, through Health Ministers. A Board that has been appointed to act in the public interest and not to represent particular sectors leads the Agency.

In reorganizing their food safety systems, EU countries cited several challenges. Many countries had to consider whether to place the new agency within the existing Ministry of Health or Agriculture or establish an autonomous authority, while also determining what responsibilities the new agency would have (GAO, 1999). For example, Ireland chose to place its new food safety authority in its Department of Health and Children (WHO, 2001), in part, to separate food safety responsibility from the promotion of the food industry, which is the responsibility of the Department of Agriculture and Food, separating food safety regulation from political pressure. On the other hand, a large number of EU countries (Finland, Denmark, Czech Republic, Estonia, Latvia, Hungary, Greece, and Romania) were not able to fully dissociate their food safety activities from possible economic and political interests related to different government ministries, and maintained their reformed food safety agencies under the influence of the Ministry of Agriculture. According to a joint report from WHO/EURO-FSAI and guidelines of WHO / FAO in 1992 on strengthening national food safety programs, such agencies should be independent of trade and economic interests and should report ideally, to the Ministry of Health. However, in practice, an independent status means that the agency is not under a ministerial supervision and would be better assured if the agency reported directly to the parliament or to another equivalent national body through the relevant Minister. In case that the above suggestion is not feasible, it is recommended that the food safety authority be placed within the Ministry of Health due to the basic mission and 
orientation to protect the health of the public. Areas where marked differences occurred in EU approaches included the division of responsibilities of risk assessment, risk management, and risk communication ("BfR / EFSA Focal Point," 2009). The survey showed that approximately half of EU countries that reorganized their NFSS kept all three areas of function together, whereas others separated risk assessment and risk communication from the risk management part. Among these EU countries, almost all gave a form of complete or partial independence to their system in order to improve program consistency. It is important to note that there was no single model for food safety authority reorganization.

Among those EU countries that undertook a reorganization of their national food safety systems, the vast majority of countries (21 out of 22 countries) tried to provide a form of complete or partial independence to their system. Furthermore, the majority of countries advanced their new food safety system with a full or partial operational / institutional division between risk assessment and risk communication, on one hand and risk management on the other.

Remarkable examples include Germany, Denmark, and The Netherlands, which reorganized their national food safety systems by using different approaches however (Neeliah \& Goburdhun, 2007); and also support that their particular social, political, and economic conditions finally determined the most appropriate food safety model for each country. Germany's new food safety agency, the Federal Office of Consumer Protection and Food Safety, functions as a coordinating body to lead food safety management, while at the same time the Federal Institute for Risk Assessment was created as an autonomous institution in order to separate risk assessment activities from risk management (Lenz, 2006; "BfR / EFSA Focal Point," 2009). Denmark centralized its system in 1997 by creating a new central agency, the Danish Veterinary and Food Administration (DVFA), in which it consolidated almost all food safety functions and activities. In parallel, they created the Danish Institute for Food and Veterinary Research that is a separate institute within DVFA, in order to support the above functions with impartial scientific re- search (Nielsen, 2006). The Netherlands centralized its system by creating a new national agency in 2002, the Food and Consumer Product Safety Authority (VWA), in which it consolidated almost all food safety functions and activities. At a later stage in 2006, they created the Risk Assessment Office (BfR), a separate body within VWA, in order to give independency to its scientific risk assessments.

Our study showed that most food safety authorities or other relevant organizations on the national level deal more often than not with risk communication, followed by risk assessment and risk management. However, fewer agencies maintain activities such as a Rapid Alarm System for Food and Feed (RASFF) contact point and the European Food Safety Authority (EFSA) focal point. Only one authority deals with food policy and preparation of draft legislation. In the other EU countries, food policy and legislation drafting is executed by relevant ministries, which are primarily political bodies.

In parallel to the changes and modifications occurring in the European Union, we have witnessed similar actions regarding the reforms of their national food safety system and the foundation of a single national food safety authority or other similar organization in non-EU countries, such as Australia, New Zealand, Canada, Norway, Iceland et al.,, serving as economic partners of EU. However, this did not happen in the United States of America, one of the main food partners of the EU, where food safety is governed by a complex system that is administered by 15 different agencies. The USDA (meat, poultry, egg products) and FDA (all food categories) are the principal federal agencies for food safety in the U.S.A. operate under numerous statutes underpinning the federal framework for ensuring the safety and quality of the food supply in the U.S. A. (Taylor, 2004; GAO, 2005). These laws give the different U.S.A. agencies regulatory and enforcement powers. Such a decentralized system required the execution of more than 70 interagency agreements, which aimed at coordinating the combined food safety oversight responsibilities of the various agencies. In addition, the federal system is supplemented by the individual 50 States, which have their own statutes, regulation, and agencies for regulating and inspecting 
the safety of food products within their territories. The federal (national) laws govern predominant by interstate commerce and not products that are produced and consumed in state.

In the case of Australia, the Australian Food Authority was set up in 1990 as a federal body to achieve national consistency in food regulation. In 1996, New Zealand and Australia decided to combine the standard-setting by creating the bi-national Australian and New Zealand, Food Standards Australia New Zealand (FSANZ). Furthermore, within New Zealand, the New Zealand Food Safety Authority was established in 2002 to improve the effectiveness of New Zealand's food safety system by coordinating and harmonizing food safety activities. Specifically, New Zealand wanted to address inconsistencies between the methods used in the Ministry of Agriculture food safety program for exports and the Ministry of Health domestic food safety program.

Canada consolidated its food inspection activities in 1997 with the creation of the Canadian Food Inspection Agency, within the Agriculture and Agri-Food Canada (AAFC), in order to bring all food inspection and enforcement programs together, which were previously operated by four different departments. Canada consolidated its food safety system and made inspection and enforcement more consistent, clarifying responsibilities, and enhancing reporting to the Canadian parliament. It also enhanced efficiency by reducing duplication and overlap in food safety activities, while at the same time reducing national spending.

Limitation of our study included the fact that we performed a qualitative assessment and did not utilize quantitative data to evaluate the cost and benefits of NFSS reforms in EU countries, due to the limited literature and available information on this topic.

\section{Conclusions}

We believe that our paper illustrates the utility of the National Food Safety Systems as well as the process of institutional change and their potential advantages for food safety. Poor operating standards may have serious negative conse- quences on public health, the economy, and the overall sustainable national development. National Food Safety Systems have been reorganized in the majority of EU countries to various extents during the past couple of decades under the umbrella of a single food safety authority or other similar organizations on the national level. We have discussed the different approaches for the establishment and operation of such systems. Areas with significant differences in approaches included whether to place the new national food safety agencies under the influence of an existing ministry or create a stand-alone agency. Another important parameter refers to the division of responsibilities for risk assessment, risk management, and risk communication. The separation of food safety activities combines significant benefits because independent scientific risk assessment supports a transparent and open process for decision-making and risk management. The vast majority of EU countries have reorganized their food safety systems by consolidating responsibilities for food safety within a single national agency to address public concern on recently highlighted national and international food crises. While the overall belief is that such changes contributed to improved effectiveness, we are unable to evaluate such reforms in a systematic way and assess previous settings that existed before the institutional changes took place. NFFS nowadays face many important challenges such as the increasing prevalence of food-borne illnesses, the emergence of new food pathogens, a rapidly evolving and expanding food technology, vastly growing international food trade, significant changes in consumers' lifestyle and consumption patterns, and rising consumer awareness on food safety. Therefore, it is crucial for EU countries and other countries aspiring to participate in international food trade to strengthen their national food safety systems in order to meet the above challenges.

We believe that there is no single optimum model for a NFSS. The establishment of any such system should fit within the cultural, economic, and political realm of each country. Nevertheless, our study revealed several laudable initiatives that have been implemented in several EU countries. For example, we assume that the initiatives adopted by Germany, The Netherlands, 
Denmark, Ireland, United Kingdom, and France regarding the reorganization of their NFSS would be beneficial to any EU country having similar cultural, economic, and political characteristics or to any other country that has not yet proceeded to major institutional changes to establish a single food safety authority (NFSA) or similar organization on the national level. In addition to the scientific literature, the above assumption is also supported indirectly by Food and Veterinary Office (FVO) reports stating that the EU countries that consolidated their food safety systems experienced higher effectiveness as compared to the previous arrangements (FVO Reports). However, the above does not preclude that other EU countries with different arrangements regarding their National Food Safety Systems would be equally successful. Nevertheless, we should point out that none of the above countries has carried out an official assessment of its consolidation and the new unified system in order to assess effectiveness compared with former systems. Future studies should focus on the new consolidated food safety systems that are operating for the past decade or so in Europe, in order to assess the advantages of such institutional changes and evaluate their overall effectiveness.

\section{References}

Berg, L. (2004). Trust in food in the age of mad cow disease: a comparative study of consumers' evaluation of food safety in belgium, britain and norway. Appetite, 42(1), $21-32$.

Berman, V. (2001). Comparative characteristics of state control of food quality and safety in various countries of the world. i. State control of quality and safety of food products in Germany and Denmark. Vopr Pitan 70(4), 31-5.

BfR / EFSA Focal Point. (2009). EU Food Safety Almanac 2009, Retrieved from http:// www.bfr.bund.de/cm/25/eu_food_safety_ almanac.pdf

Boutrif, E., \& Piniero, M. (2003). Food control systems. Forum Nutr. 56, 418-21. Review.

Butler, D. (1997). How bse crisis forced europe out of its complacency. Nature, 385(6611),
6-7. PMID: 8985232 [PubMed - indexed for MEDLINE].

de Jonge, J., van Trijp, H., Jan Renes, R., \& Frewer, L. (2007). Understanding consumer confidence in the safety of food: its two-dimensional structure and determinants. Risk Anal, 27(3), 729-40. PMID: 17640219 [PubMed - indexed for MEDLINE].

Elmi, M. (2004). Food safety: current situation, unaddressed issues and the emerging priorities. East Mediterr Health J, 10(6), 794800. PMID: 16335766 [PubMed - indexed for MEDLINE].

FAO/WHO. (2003). Assuring food safety and quality: guidelines for strengthening national food control systems. Retrieved from http://www.fao.org

Fuentes, V. (2010). Food risk communication. [Online] Available [Accessed 22/11/10]. Retrieved from http://www.legalagrifood. com

GAO. (1999). Food safety: experiences of four countries in consolidating their food safety systems. (gao/rced-99-80, apr. 20).

GAO. (1994). General accounting office - food safety: a unified, risk-based food safety system needed. (gao/t-rced-94-223, may 25).

GAO. (2005). General accounting office - food safety: steps should be taken to reduce overlapping inspections and related activities. (gao / rced-05-549t, may 17).

Garcia, R., \& Jukes, D. (2004). The spanish system of food controls - its administration and enforcement. Food Control, 15, 51-59.

Gaynor, C. (2007). Food safety controls in europe-challenges and opportunities. JAOAC Int, 90(1), 1-5. PMID: 17373431 [PubMed - indexed for MEDLINE].

Hadjigeorgiou, A., Soteriades, E., Gikas, A., Philalithis, A., Psaroulaki, A., \& Tselentis, Y. (2012). Establishment of a national food safety authority for cyprus: a comparative proposal based on the european paradigm. Food Control, 30(2013), 727-736.

Halkier, B., \& L., H. (2006). Shifting responsibilities for food safety in europe: an introduction. Appetite, 47(2), 127-33. Epub 2006 Jun 21 
James, W. (2004). Food and health in europe: a new basis for action. WHO Reg Publ Eur Ser, (96):i-xvi, 1-385. back cover. Review. PMID: 15038063 [PubMed - indexed for MEDLINE].

Kaferstein, F., \& Abdussalam, M. (1999). Food safety in the $21^{s} t$ century. Bulletin of the World Health Organization, 77, 347-51.

Lang, T., Millstone, E., \& Rayner, M. (1997). Food standards and the state. Discussion Paper 3, Centre for Food Policy. London: Thames Valley University, 1997.

Lenz, T. (2006). Lack of clarity: changing roles and responsibilities in the german food system. Appetite, 47, 152-160.

Lupien, J. (2007). Prevention and control of food safety risks: the role of governments, food producers, marketers, and academia. Asia Pac J Clin Nutr, 16 Suppl 1, 74-9. PMID: 17392080 [PubMed - indexed for MEDLINE].

Lupien, J. (2002). The precautionary principle and other non-tariff barriers to free and fair international food trade. Crit Rev Food Sci Nutr, 42(4), 403-15. PMID: 12180779 [PubMed - indexed for MEDLINE].

Maudoux, J., Saegerman, C., Rettigner, C., Houins, G., Van Huffel, X., \& Berkvens, D. (2006). Food safety surveillance through a risk based control programme: approach employed by the belgian federal agency for the safety of the food chain. Vet $Q, 28(4)$, $140-54$.

Millstone, E., \& van Zwanenberg, P. (2000). A crisis of trust: for science, scientists or for institutions? Nat Med, 6(12), 1307-8. PMID: 11100103 [PubMed - indexed for MEDLINE].

Millstone, E., \& van Zwanenberg, P. (2002). The evolution of food safety policy/making institutions in the uk, eu and codex alimentarius. Social Policy and Administration, 36(6), 593-609.

Millstone, E., Lang, T., Naska, A., Eames, M., Barling, D., van Zwanenberg, P., \& Trichopoulou, A. (2000). European policy on food safety: comments and suggestions on the white paper on food safety. Trends in Food Science and Technology, 11(12), 458466.
Mostl, K. (2003). Bovine spongiform encephalopathy (bse): the importance of the food and feed chain. Forum Nutr, 56, 3946. PMID: 15806951 [PubMed - indexed for MEDLINE].

Neeliah, S., \& Goburdhun, D. (2007). National food control systems: a review. Food Reviews International, 23, 35-51.

Nielsen, A. (2006). Contesting competence change in the danish food safety system. sciencedirect. Appetite, 47, 143-151.

Pina, M., Ferrer, C., Rodrigo, M., Klein, G., \& Martínez, A. (2006). Organization of risk analysis in the eu and the new eu food legislation. Dtsch Tierarztl Wochenschr, 113(11), 407-12. PMID: 17147150, [PubMed - indexed for MEDLINE].

Post, D. (2006). The precautionary principle and risk assessment in international food safety: how the world trade organization influences standards. Risk Anal, 26(5), 125973. PMID: 17054530 [PubMed - indexed for MEDLINE].

Regmi, A., \& Bernstein, J. (2003). International evidence on food consumption patterns. Technical Bulletin Number 1904. Economic Research Service, USDA.

Robertson, A., Tirado, C., Lobstein, T., Jermini, M., Knai, C., Jensen, J., ... James, W. (2004). Food and health in europe: a new basis for action. WHO Reg Publ Eur Ser, (96):i-xvi, 1-385. PMID: 15038063 [PubMed - indexed for MEDLINE].

Silano, M., \& Silano, V. (2007). The fifth anniversary of the european food safety authority (efsa): . Mission, organization, functioning and main results. Fitoterapia 8:23.

Springston, J., \& Weaver Lariscy, R. (2005). Public relations effectiveness in public health institutions. J Health Hum Serv Adm, 28(2), 218-45. PMID: 16521670, [PubMed - indexed for MEDLINE].

Taylor, M. (2004). Lead or react? a game plan for modernizing the food safety system in the united states. Food Drug Law J, 59(3), 399-403. PMID:15586989, [PubMed - indexed for MEDLINE].

Terragni, L. (2006). A country that never had a bse crisis: Consensus and tensions in trans- 
National Food Safety Systems $\mid 117$

forming the Norwegian food system. Appetite 47, 170-176.

Tselentis, G. (2008). The sanitary safety and the precautionary principle: Athens, Oikotopia: Issue 46, 76-79. Greek Ed.

Wales, C., Harvey, M., \& Warde, A. (2006). Recuperating from bse: the shifting uk institutional basis for trust in food. Appetite, 47(2), 187-95. Epub 2006 Jun 19.

White paper on food safety. (2000). Brussels, 12 January, 2000. COM .1999. 719 Final. DG SANCO. Available from: Retrieved from http://europa.eu.int/comm/dg24/library/ pub/pub06_en.pdf

WHO. (1992). Guidelines for strengthening a national food safety programme. Geneva. World Health Organization, 1992 (unpublished document: WHO/FNU/FOS/92.2).

WHO. (2001). Improved coordination and harmonization of national safety control services. World Health Organization Regional Office for Europe, Copenhagen, Denmark, 2001.

William, J. (2000). Food agencies and food standards: the future regulatory mechanism for the food trade. Nutrition, 16(7/8).

World Bank. (2004). World development indicators database, september 2004. World Bank. Available online: Retrieved from http : / / www . worlbank . org / data / databytopic/GDP.pdf 